\title{
Çevreye Duyarlı Konaklama Tesislerinin Misyon ve Vizyonlarının Küresel Sürdürülebilir Turizm Kriterleri Açısından Değerlendirilmesi
}

\author{
Evaluation of the Mission and Vision of Environmentally Friendly \\ Accommodation Facilities in terms of Global Sustainable Tourism Criteria
}

\section{Öz}

Bu çalışmada, çevreye duyarl konaklama tesislerinin misyon ve vizyonlarında yer alan ifadelerin sürdürülebilir turizm kriterleri temel alanlarına bă̆lı olarak ne şekilde yer aldı̆̆g dolayısıyla dağılımlarının verilerle hesaplanması ve ortaya konulması amaçlanmıştır. Çalışmanın teorik alt yapısı atfetme teorisine dayandırılmaktadır. Çalışmada içerik analizi tarama yöntemi kullanılmıştır. Çalışmanın evreni Türkiye'de bulunan çevreye duyarl tesis etiketine sahip konaklama tesisleridir. Toplam 478 Çevreye Duyarl Konaklama Tesisi (yeşil yıldızlı tesis) bulunmaktadır. "Çevreye Duyarl Tesisler" listesinde yer alan tesislerin internet siteleri 07.04.2020 ile 16.04.2020 tarihleri arasında ziyaret edilmiştir. Çalışmada elde edilen veriler doğrultusunda konaklama tesislerinin genelinin misyon ve vizyon tanımlarına ulaşılamadığı görülmektedir. Ulaşılabilen misyon ve vizyon cümlelerinde sürdürülebilir turizm kriterleri dikkate alınarak sadece kelime ve kavramlar ele alınıp dağılım yapılmıştır. Kavram ve kelime dağılımına bakıldı̆̆ııda sürdürülebilir turizm kriterlerinden olan çevre ve sürdürülebilir yönetime daha çok değinilmektedir. Sürekli değişen ve rekabet şiddetinin arttı̆̆ı bir ortamda her daim başarının da sürdürülebilmesi için konaklama tesisleri bu faaliyetlere daha çok dikkat etmesi gerekmektedir.

\section{Abstract}

In this study, it was aimed to calculate and reveal the distribution of the expressions contained in the missions and visions of environmentally friendly accommodation facilities with data, so that they are located depending on the main areas of sustainable tourism criteria. The theoretical background of the study is based on attribution theory. Content analysis scanning method was used in the study. The universe of the study is accommodation facilities with an environmentally friendly facility label located in Turkey. There are a total of 478 environmentally friendly accommodation facilities (Green star facility). The internet sites of the facilities included in the list of environmentally sensitive facilities " were visited between 07.04.2020 and 16.04.2020. According to the data obtained in the study, it is observed that the mission and vision definitions of the accommodation facilities in general cannot be reached. In the mission and vision sentences that can be achieved, only words and concepts were considered and distributed, taking into account the criteria for Sustainable Tourism. Considering the concept and word distribution, environment and sustainable management, which are among the sustainable tourism criteria, are more frequently mentioned. Accommodation facilities should pay more attention to these activities in order to maintain success in an environment that is constantly changing and increasing the intensity of competition.

\section{Giriş}

Günümüzde gerek kentleşmenin artması gerek sanayinin gelişmesi gerekse nüfus artışında hızlı değişimlerin olması çevre sorunlarını da beraberinde getirmektedir. Diğer yandan bu çevre sorunları turizm sektörünü de etkisi altına almaktadır. Bu açıdan bakıldığında turizmin çevre ile etkileşim halinde olduğu görülmektedir. Turizm sektörünün en önemli bileşiminde yer alan konaklama tesisleri de yine çevre ile ilişki içerisindedir ve çevreye yapılan zararı ortadan

\begin{abstract}
Elif Acuner
Dr. Öğr. Üyesi, Recep Tayyip Erdoğan Üniversitesi, Ardeşen Turizm Fakültesi Turizm İşletmeciliği Bölümü, elif.acuner@erdogan.edu.tr Orcid No: https://orcid.org/0000-00027769-8705
\end{abstract}

\section{Emel Ergin \\ Yüksek Lisans Öğrencisi, Recep Tayyip Erdoğan Üniversitesi, Lisansüstü Ĕ̆itim Enstitüsü Turizm İşletmeciliği Bilim Dall,emel_ergin19@erdogan.edu.tr Orcid No: $h$ ttps://orcid.org/0000-0001- 7651-7100}

Article Type / Makale Türü

Research Article / Araştırma Makalesi

Anahtar Kelimeler

Yeşil Yildız, Misyon, Vizyon, Sürdürülebilir Turizm Kriterleri, Çevreye Duyarl Tesis.

Keywords

Green Star, Mission, Vision, Sustainable Tourism Criteria, Environmentally Friendly Facility.

\section{Bilgilendirme: \\ Bu makale, 03-05 Aralık tarihlerinde Gümüşhane'de gerçekleşen Uluslararası Bilimsel Araştırmalar Kongresi'nde bildiri olarak sunulmuştur}

JEL Codes: Z32, Z33, Z39.

Submitted: $\quad 15$ / $06 / 2021$ Accepted: $\quad 10 / 08 / 2021$ 
kaldırmada ya da en aza indirmede çevre yönetimini kullanmaktadır. Çevre yönetiminde konaklama tesisleri, sürdürülebilir doğa ve çevre için gereken şartları yerine getirmeye çalışmaktadır. Bu bağlamda çevreye duyarlı konaklama tesisleri bulunmaktadır. Konaklama tesisleri, küresel sürdürülebilir turizm kriterleri ile birlikte çeşitli uygulamalar yapmakta ve yönetim anlayışında sürdürebilir turizmi sağlamaya çalışmaktadır. Sürdürülebilirlik kavramı, çevreye verilen zararların en alt düzeye indirilmesine yönelik faaliyetleri kapsamaktadır. Sürdürülebilir turizmin kapsamı ise çevreye ve kaliteye dayanmaktadır. Çevreye ve kaliteye odaklanan tüketiciler, eskiye nazaran daha bilinçli tercih yapmakta ve daha fazla beklenti içerisine girmektedirler. Bilinçli tercih yapan tüketiciler, gelecekğe daha yaşanılabilir bir dünya bırakmak için çevre odaklı yaklaşımlar sergilemektedirler. Tüketiciler, çevre dostu olan ürünleri daha fazla tercih etmekte ve işletmelerin de bu yönde hareket etmelerini sağlamaktadırlar. Çevreye duyarlı konaklama tesisleri de bu beklentileri karşılamak için rekabet avantajı sağlamaya çalışmaktadırlar. Bu yoğun rekabet ortamında çevreye duyarlı konaklama tesisleri, misyon ve vizyon oluşturarak rakiplerine karşı rekabet avantajı oluşturabilmektedirler. Bu sayede çevreye duyarlı konaklama tesislerinin resmi internet sitelerinde yer alan misyon ve vizyonlarına ilişkin cümlelerde sürdürülebilir turizm için yapılmış olan faaliyetler ile küresel sürdürülebilir turizm kriterlerine yer verilmesi tesis için önemli bir avantaj sağlayacaktır. Bu durum, tüketicide olumlu bir etki bırakabilecek; tüketicinin memnuniyetini arttırabilecek ve tesiste kalış süresini de uzatabilecektir.

Yukarıda bahsi geçen husulardan yola çıkarak bu çalışmada, Çevreye Duyarlı Konaklama Tesislerinin misyon ve vizyon cümlelerinde yer alan ifadelerin sürdürülebilir turizm kriterlerinin temel alanlarına bağlı olarak ne şekilde yer aldığı üzerinde durulmuş, buna yönelik dağılımlar verilerle hesaplanmış ve ortaya konulmuştur.

$\mathrm{Bu}$ amaca bağlı olarak da araştırma dört bölümden oluşmaktadır. Birinci bölümde post modern turizm kapsamında sürdürülebilir turizm kavramı üzerinde durulmuş, sürdürülebilir turizm kriterlerine değinilmiş, çevreye duyarları konaklama tesislerinden bahsedilmiş ve misyon-vizyon kavramları ele alınmış ve bunların birbirleri ile aralarındaki ilişki üzerinde durularak kavramsal çerçeve başlığı altında yer verilmiştir. İkinci bölümde ise benzer çalışmalar ele alınarak literatür taramasına yer verilmiştir. Üçüncü bölümde elde edilen verilerin yöntem ve teknikleri açıklanmıştır. Dördüncü bölümde elde edilen veriler üzerinden analizler yapılmıştır. Bu analizlerde nitel araştırma tekniklerinden biri olan içerik analizinden yararlanılmıştır. Yapılan analiz sonucunda ise birtakım bulgulara ulaşılmıştır. Sonuç bölümünde ise bu bulgulardan yola çıkarak elde edilen sonuçlar doğrultusunda yorum ve önerilerde bulunulmuştur.

\section{Kavramsal Çerçeve}

Modern sonrası dönem olarak da adlandırılan Post-modern turizm anlayışı kitle turizminin aynılaşmaya sebep olduğu düşüncesi ile farklılık arayan kesimi artık tatmin etmemesi nedeniyle daha esnek turistik ürünlere doğru bir eğilim ortaya çıkarmıştır (Tayara ve Özel, 2019: 100-101). Post-modern turizm dönemi, turistleri bireyselliğe, çeşitli alternatif ürünlere, zaman ve mekan gibi kavram kısıtlılığından uzaklaştırmaya ve çevreye duyarlılığa yönlendirmektedir. Bu dönemde turizmde alternatif arayışlar ile sürdürülebilirlik kavramı etrafında şekillenmiştir. Sürdürülebilirlik; "genel yaşam kalitesini koruyarak, doğal kaynaklara sürekli erişimin să̆lanmasını, çevre üzerinde kahıı zararlar verecek etkinliklerin engellenmesini ve gelecek kuşakların ihtiyaçlarım karşılayacak kaynakların tehlikeye atılmadan kullanılmasımı öneren bir yaklaşımdır" şeklinde tanımlanmıştır (Akoğlan Kozak vd., 2013: 17). Sürdürülebilir turizm kavramı; doğal ve kültürel çevreye hassas, biyoçeşitliliği korumayı amaç edinmiş, gelecek kuşakları turizme kazandırmayı hedefleyen, uzun vadeli düşünen ve yerel toplumları destekleyen bir turizm anlayışıdır(Yurtsal, 2019: 62).Sürdürülebilir turizm faaliyetleri turizm tesisleri içinde önemli hale gelmiştir. Post modern turizm anlayışında turizm tesislerinin turistlerin bireysel olarak istek ve ihtiyaçlarına yönelik turistik ürünler ürettiği görülmektedir (Güneren ve Karakuş, 2015: 476). Günümüz tüketicilerinin satın aldığı ürün ve hizmetler, hayatlarında sosyal ve duygusal değerler kazandırmaktadır. Konaklama tesisleri misafirlerin duygu ve hislerine yönelen, kişiye özgü ve unutulmaz deneyimler ile birlikte de farklılaşmayı sağlayarak rekabetçi avantaj elde 
edebilmektedir (Güzel, 2014: 1). Bu bağlamda pazarlama alanındaki atfetme teorisi kullanılmaktadır. Atfetme teorisi, yapılan bir uygulamada ya da bir olaydaki durumların nedenlerine inerek anlamaya çalışmakta ve çeşitli yargılara varmaktadır. Çevreye Duyarlı Konaklama Tesisleri (yeşil yıldız) çevreye duyarlı tesis olma özelliğini daha çok ön planda tutup bu doğrultuda uygulanan faaliyetlerini yansıtarak misafirlerin farkındalıklarını artırıp tercih etmelerine neden olabilirler. Rekabet üstünlüğü açısından avantaj sağlayıp satın alma davranışının gerçekleşmesine ikna edebilirler. Atfetme teorisi ile özellikle sürdürülebilir ürünler isteyen tüketiciler için misyon ve vizyon cümlelerindeki sürdürülebilirlik ile ilgiliatıflarda bulunabilirler. Böylelikle çevreye duyarlılığı atfederler ve bu belgeye sahip olmayan tesislere nazaran çevreye duyarlı tesisler daha fazla tercih edilmiş olabilirler.

Konaklama tesislerinde çevrenin korunmasına önem veren Türkiye'de sürdürülebilir turizm kapsamında çevre bilincinin gelişmesi, çevrenin korunması, turizm tesislerini çevreye olumlu katkılarının teşvik edilmesi ve uygulanması amacıyla, “...1993 yılından itibaren talep eden ve istenilen nitelikleri taşıyan konaklama tesislerine Kültür ve Turizm Bakanlığı tarafindan Çevre Dostu Kuruluş Belgesi (Çam Simgesi) verilmiştir" (Kültür ve Turizm Bakanlığ1, 2020). Türkiye'de her geçen gün çevrenin korunmasına yönelik faaliyetlerin önemi daha fazla artmaktadır (Gönen, 2018: 353). Kültür ve Turizm Bakanlığı'ndan Turizm İşletme Belgesi almış tesisler, gerekli kriterleri sağladıkları takdirde Çevreye Duyarlı Konaklama Tesis (Yeşil Yıldız Simgesi) Belgesi alabilirler. Bu belge konaklama tesislerine 2008 yılı itibari ile verilmeye başlanmıştır (Oğuz ve Yılmaz,2018: 53). Çevreye Duyarlı Konaklama Tesisleri için uygulanmakta olan sınıflandırma formu aracılığı ile konaklama tesislerinin sınıfına göre asgari puanları bulunmaktadır. Konaklama tesisleri istenilen yeterli asgari puanı aldıkları takdirde Çevreye Duyarlı Konaklama Tesisi Belgesi almaya hak kazanırlar. Her iki yılda bir belgeler Bakanlıkça denetlenerek Yeşil Yıldızın tesis açısından devamlılığı sağlanır (Giritlioğlu ve Güzel, 2015: 891). Bakanlıkça belirlenen Çevreye Duyarlı Konaklama Tesisi Belgesi Tebliği, “...enerji, su, çevreye zararl maddelerin tüketiminin ve atı miktarının azaltılmasını, enerji verimliliğinin arttıılmasını, yenilenebilir enerji kaynaklarının kullanımının teşvik edilmesini, konaklama tesislerinin yatırım aşamasından itibaren çevreye duyarl olarak planlanmaların ve gerçekleştirilmelerini, tesisin çevreye uyumunu, çevreyi güzelleştirici düzenleme ve etkinliklerini, ekolojik mimariyi, çevreye duyarllik konusunda bilinçlendirmeyi, eğitim să̆lanmasın ve ilgili kurum ve kuruluşlarla işbirliği yapılmasını kapsamaktadır" (Kültür ve Turizm Bakanlığı, 2020).

Küresel Sürdürülebilir Turizm Kriterleri: "sürdürülebilir turizm" dünyasında ortak bir anlayış sağlamak amacıyla oluşturulmuştur. Konseyin amacı her büyüklükteki işletmenin daha sürdürülebilir olması için temel yönergeler aracılığı ile hizmet etmek ve işletmelerin bu küresel kriterleri karşılayan sürdürülebilir turizm programlarını seçmelerine yardımcı olmaktır. Konseyin bir diğer amacı büyüyen pazarda sürdürülebilir ürünler için daha fazla pazara erişim sağlamak ve sürdürülebilir turizm programları için rehberlik etmektir (Control UnionCertifications, 2020). Sürdürülebilir turizm kriterleri dört temel alan başlığı üzerinde düzenlenmiş olup bu başlıklar şu şekildedir: Etkili sürdürülebilirlik yönetimi, yerel toplum için sosyal ve ekonomik faydaların en üst düzeye çıkarılması, kültürel mirasın artırılması ve çevreye olumsuz etkilerin azaltılmasıdır (Acuner, 2015: 68). Ayrıca bu dört temel alan kriterinin alt başlıkları da bulunmaktadır. Bunlar: Etkili sürdürülebilir yönetimin gösterilmesi; sürdürülebilirlik yönetim sistemi, yasal uygunluk, raporlama ve iletişim, personel katılımı, müşteri deneyimi, doğru tanıtım, binalar ve altyapı "uyumluluğu, etki ve bütünlük, sürdürülebilir uygulamalar ve materyaller, herkes için erişim", arazi suyu ve mülkiyet hakları, bilgi ve yorumlama, hedef katılımıdır. Yerel topluma sosyal ve ekonomik faydaları; topluluk desteği, yerel istihdam, yerel satın alma, yerel girişimciler, sömürü ve taciz, eşit fırsat, iyi çalışma, topluluk hizmetleri, yerel geçim kaynaklarıdır. Kültürel miras; kültürel etkileşimler, kültürel mirasın korunması, kültür ve mirasın sunulması, eserleridir. Çevreye olan faydaları; kaynakları koruma; "çevreye duyarlı satın alma, verimli satın alma, enerji tasarrufu, su tasarrufu", kirliliğin azaltılması; "sera gazı emisyonları, nakliye, atık su, katı atık", biyoçeşitliliği, ekosistemleri ve manzaraları korumak;" biyoçeşitliliğin korunması, istilacı türler, doğal yerlere ziyaretler, yaban hayatı etkileşimleri, hayvan sağlı̆̆ı, yaban hayatı hasadı ve ticaretidir" (GSTC, 
2016: 3-11). Çalışmada, Çevreye Duyarlı Konaklama Tesislerinin internet sitelerinde misyon ve vizyon cümleleri varlığı durumuna bakılarak, misyon ve vizyon cümlelerinde ki ifadelerinde Küresel Sürdürülebilir Turizm Konseyi (GSTC) Kriterlerinin temel alan başlıklarının dağılımı incelenmiştir.

İşletmelerde kurumsal kimliklerine katkı sağlayan amaç ve hedef gibi özellikler akla geldiği zaman işletmeleri diğer işletmelerden ayıran misyon ve vizyon tanımları işletmelerin kimlikleri için önem taşımaktadır (Sabuncuoğlu ve Gök, 2008: 126). Misyon ve vizyon bir işletmenin imajını ortaya koymaktadır (Kılıç,2010: 93-94). Misyon ve vizyon tanımları işletmeleri daha ileri taşırken aynı zamanda işletmelerin varlıklarını da ortaya koymaktadır (İnce, 2015: 146). Misyon işletmenin amacını üstlenmektedir. Bir misyon tanımının müşterilerin ve diğer paydaşların da değer verdiği konuları içermesi gerekmektedir (Soygür, 2018: 990). Vizyon tanımı bir işletmenin daha önce hiç düşünmediği ya da başaramadığı fakat gelecekte başarmayı düşündüğü özgün düşünceler sonucu ortaya çıkmaktadır (Civelek Oruç ve Zengin, 2015: 36-38). Bu şekilde işletmeler misyon ve vizyonlarını oluşturarak rakiplerine karşı yoğun rekabetin olduğu ortamda avantaj sağlayabilirler. Rekabet avantajı sağlarken diğer taraftan rakiplere karşı rekabet üstünlüğü sağlamaktadırlar. Misyonunu bilmeyen ve vizyon sahibi olmayan işletmeler yoğun rekabet ortamında kendilerine yer bulamayacaklardır (Muslu, 2014: 152-169). Bu doğrultuda misyon ve vizyon cümlelerinin önemi de büyüktür.

\section{Literatür Taraması}

Literatür incelendiğinde çevreye duyarlı tesisler ile ilgili birçok çalışmaya rastlanmaktadır: Doğancili ve Akbulut (2015), Ertaş vd. (2017), Ertaş (2018) çalışmalarında, konaklama işletmelerinin çevreye olan duyarlılığ internet siteleri üzerinden incelemiş olup internet sitelerinde uygulama hakkında çok fazla bilgi verilmediği sonucuna ulaşmışlardır. Kim (2009), Giritlioğlu ve Güzel (2015), Türk ve Harbalıŏglu (2015), Ünüvar (2016), Satar ve Güneş (2017), Deste vd. (2018) çalışmalarında, konaklama işletmelerinin yönetiminde yeşil uygulama faaliyetlerinin (çevreye duyarlı, sürdürülebilir turizm, yeşil yıldız kriterleri, çevre yönetimi, sosyal sorumluluk, yeşil yönetim gibi) uygulanıp uygulanmadığı ve bu faaliyetlerden ne kadar farkındalık içerisinde olduklarını incelemişlerdir. İlgili faaliyetlere yönelik eksiklerin olduğunu belirterek çalışmaların yeterli düzeyde olmadığı sonucuna ulaşmışlardır. Güneş (2011), Gümüş (2014), Akova vd. (2015), Cömert ve Özata (2016), Büyükşalvarcı vd. (2017), Türk ve Kara (2018), Rani ve Raj (2020) çalışmalarında ise uygulanan faaliyetlerin olumlu sonuçları olduğunu ve pazar payı, fiyat, imaj, maliyet, hizmet kalitesi, müşteri ve çalışan tatmini, kârlılık, verimlilik ve rekabet gibi başarı göstergelerine katkı să̆ladığını belirtmişlerdir. Çeşitli araştırmacılar çalışmalarında, uygulanan faaliyetler olumlu yönde etki etmiş olsa bile konaklama işletmelerinin özelliklerine göre bu faaliyetlerde farklılıkların olduğunu da savunmuşlardır (Dilek ve Atay, 2012; Özdemir vd. 2016). Konaklama işletmelerinde yeşil yıldızlı tesis özelliğinin misafirlerin niyet ve tutumlarını olumlu yönde etkilediğini ortaya koyan çalışmalar da mevcuttur(Çetin Gürkan vd. 2015; Özer vd. 2015; Verma ve Chandra, 2016; Yıldız ve Kılıç, 2016; Kement ve Çavuşoğlu, 2017; Kement, 2018; Oğuz ve Yılmaz, 2018; Yıldırım vd. 2018). Aylan ve Sezgin, (2016), Yıldız ve Kılıç, (2016) çalışmalarında da yeşil yıldızlı tesis özelliğinin demografik özelliklere göre tutum ve niyette farklılıklar gösterdiği sonucuna ulaşmışlardır. Ardıç Yetiş (2018) çalışmasında, konaklama işletmelerinin çevre dostu uygulamaları benimsemeleri açısından zor olmadığı, turizmin sürdürülebilirliğinin yeşil pazarlama ile mümkün olacağı ve işletmelerin maliyetleri açısından da bunun doğru bir yol olacağı sonucuna ulaşmıştır. Konaklama tesislerinin yeşil yıldız unvanının ekonomik açıdan büyük ölçüde katkısı olduğu gösteren çalışmalar da mevcuttur (Zengeni vd. 2013; Mesci, 2014; Doğan ve Ertaş, 2018; Güngör vd. 2018). Araştırmacılar çevreye duyarlı tesislerin rekabet gücünü arttırdığını da savunmaktadırlar (Akdağ vd. 2014; Doğan ve Ertaş, 2018). Çavuşoğlu ve Durmaz, (2019) çalışmalarında müşterilerin tekrar ziyaret etme niyetlerinde yeşil imajın düzenleyici rolünün olmadığı sonucuna ulaşmıştır. Mercan (2016) çalışmasında, katılımcıların en çok; kâğıt, teneke, plastik, şişe vb. geri dönüşümlere önem verdiğini belirtmiştir. Kullanılmış, dönüştürülebilir ürünlerin satın alınması ve kullanılmasının konaklama 
işletmelerinde en düşük düzeyde olduğunu da vurgulamıştır. Akdemir (2019) çalışmasında, yöneticiler açısından konaklama işletmelerinin çevresel değişimlere neden olduğu sonucuna ulaşmıştır. Ayrıca yöneticilerin çevresel bozulmanın kış konaklama işletmelerinden daha çok kıyı ve şehirlerde bulanan konaklama işletmelerini etkileyeceği yönünde düşüncelere sahip olduklarını vurgulamıştır. Mcnamara ve Gibson (2008) çalışmalarında, çevresel girişimlerin zayıf bir şekilde ele alındığı üzerine vurgu yapmışlar ve bunların uygulanmasının yararları konusunda konaklama tesislerinin kendi yöneticileriyle güçlü bir iletişim içinde olmadığı sonucuna ulaşmışlardır.

\section{Araştırmanın Yönetimi}

Araştırmanın ana sorusu: "Çevreye duyarlı tesis etiketine sahip konaklama tesislerinin misyon ve vizyonuna ilişkin ifadelerinde sürdürülebilir turizme yönelik kriterlerin temel alan başlıklarının dağılımı ne şekildedir? Çalışmanın alt araştırma soruları;

Alt Araştırma Sorusu 1: Sürdürülebilir turizm kriterlerinin temel alan başlıklarından "çevre" kriterinin misyon ve vizyon cümlelerindeki ifadelerde vurguları nelerdir?

Alt Araştırma Sorusu 2: Sürdürülebilir turizm kriterlerinin temel alan başlıklarından "sürdürülebilir yönetim" kriterinin misyon ve vizyon cümlelerindeki ifadelerde vurguları nelerdir?

Alt Araştırma Sorusu 3: Sürdürülebilir turizm kriterlerinin temel alan başlıklarından "yerel topluma sosyal ve ekonomik fayda" kriterinin misyon ve vizyon cümlelerindeki ifadelerde vurguları nelerdir?

Alt Araştırma Sorusu 4: Sürdürülebilir turizm kriterlerinin temel alan başliklarından “kültürel miras" kriterinin misyon ve vizyon cümlelerindeki ifadelerde vurguları nelerdir?

Çalışmada teorik alt yapısı atfetme teorisine dayandırılmaktadır. Çalışmada tarama yöntemi kullanılmıştır. Çalışmanın verileri içerik analizi ile değerlendirilmiştir. Çalışmanın evreni Türkiye'de bulunan Çevreye Duyarlı Tesis etiketine sahip konaklama tesisleridir. İlgili tesislere Kültür ve Turizm Bakanlığı'nın resmi internet sitesinden ulaşılmıştır. Toplam 478 Çevreye Duyarlı Konaklama Tesisi (yeşil yıldızlı tesis) bulunmaktadır. "Çevreye Duyarlı Tesisler" listesinde yer alan tesislerin internet siteleri 07.04.2020 ile 16.04.2020 tarihleri arasinda ziyaret edilmiştir. İnternet sitelerinin dinamik yapısı nedeniyle sadece bir kez ziyaret edilmiştir. Çalışmada öncelikle çevreye duyarlı tesis belgesine sahip konaklama tesislerinin bulunduğu iller, tesis türü ve tesis sinıfı verilerinin yüzde ve frekans dağılımları incelenmiştir. Daha sonra çalışmada tesislerin internet sitelerine ulaşılabilirliğine bakılmıştır. İnternet sitesi olan tesislerin ise misyon ve vizyon cümlesi olup olmadığı kontrol edilmiş, var olan misyon ve vizyon cümlelerinde sürdürülebilir turizm kriterleri temel alanları olan çevre, sürdürülebilir yönetim, yerel topluma sosyal ve ekonomik fayda, kültürel miras kriterlerine ilişkin özellikleri taşıyan cümle yapıları tespit edilmiştir. Cümle yapılarında bu kriterleri barındıran tüm kavramlar not alındıktan sonra kodlamaları yapılmıştır. İçerik analizi sonucunda nicel yöntemlere ait göstergeler olan frekans ve yüzde dağılımları kullanılarak bulgular kısmında sunulmuştur.

$\mathrm{Bu}$ çalışmada, Çevreye Duyarlı Konaklama Tesislerinin misyon ve vizyonlarında yer alan ifadelerin sürdürülebilir turizm kriterleri temel alanlarına bağlı olarak ne şekilde yer aldığı dolayısıyla dağılımlarının verilerle hesaplanması ve ortaya konulması amaçlanmıştır.

Araştırma yöntemlerinin hepsinde olduğu gibi elde edilen verilerin geçerli ve güvenilir olması gerekmektedir. Geçerlik ve güvenirlik için örneklemin iyi seçilmesi gerekmektedir (Öğülmüş,1991:226). Araştırma, çevreye duyarlı konaklama tesislerini kapsadığ1 için ve örneklem sadece bu konaklama tesislerinin dâhil edilerek yapıldığ seçildiği düşünülmektedir. Ayrıca kategoriler açıç̧a belirtilmiş, oluşturulan kategorilerin nereden alındığı vurgulanmış, aynı kategoriler farklı zamanlar da aynı kodlama uygulanmış ve sonuçların aynı olduğuna dair kontrolleri yapılmıştır. Buradan hareketle, araştırmada kategorilere nasıl ulaşıldığı, nasıl oluşturulduğu ve bulunan sonuçların ayrıntılı olarak açıklandığı göz önünde bulundurularak araştırmanın geçerli ve güvenilir olduğu düşünülmektedir. 


\section{Bulgular}

Türkiye' de bulunan 478 adet Çevreye Duyarlı Konaklama Tesisleri (yeşil yıldızlı tesis) toplamda 36 ile dağılmış olup Antalya 245 tesis ile en fazla yeşil yıldızlı konaklama tesisine sahip İ'dir.

Antalya 245 tesis ile çevreye duyarlı konaklama tesislerinin \%51,3' ünü kapsamaktadır. İstanbul, 64 tesisle \%13,4'ünü, Muğla 49 tesisle \%10,3'ünü, İzmir 29 tesisle \%6,1'ini, Ankara 21 tesisle \%4,4'ü ile ilk beşte yer almaktadırlar. İllere ait bütün veriler ise Tablo1 de yer almaktadır.

Çevreye duyarlı konaklama tesislerinin tesis türüne göre dağılımına bakıldığında, 380 adet otel bulunmaktadır ve oteller bu sayı ile toplam tesislerin \%79,5' ini kapsamaktadır. Tesislerin \%6,7'si kapsayan tatil köylerinin sayısı 32' dir. Sırasıyla diğerleri; termal otel 18, özel tesis 17, butik otel ise 13 olmak üzere ilk beşte yer almaktadırlar.

Tablo 1. Çevreye Duyarlı Konaklama Tesislerinin Dağılımlarına İlişkin Bilgiler

\begin{tabular}{|c|c|c|c|c|c|}
\hline Değişken Grupları & (f) & $\%$ & Değişken Grupları & (f) & $\%$ \\
\hline İller & & & Tesis Türü & & \\
\hline Antalya & 245 & 51.3 & Otel & 380 & 79.5 \\
\hline İstanbul & 64 & 13.4 & Tatil Köyü & 32 & 6.7 \\
\hline Muğla & 49 & 10.3 & Termal Otel & 18 & 3.8 \\
\hline İzmir & 29 & 6.1 & Özel Tesis & 17 & 3.6 \\
\hline Ankara & 21 & 4.4 & Butik Otel & 13 & 2.7 \\
\hline Bursa & 6 & 1.3 & Golf & 6 & 1.3 \\
\hline Eskişehir & 5 & 1.0 & Apart Otel & 6 & 1.3 \\
\hline Aydin & 5 & 1.0 & Turizm Kompleksi & 3 & 0.6 \\
\hline Afyonkarahisar & 5 & 1.0 & Pansiyon & 1 & 0.2 \\
\hline Konya & 4 & 0.8 & Kongre ve Sergi Merkezi & 1 & 0.2 \\
\hline Gaziantep & 4 & 0.8 & B Tipi Tatil Sitesi & 1 & 0.2 \\
\hline Adana & 3 & 0.6 & & & \\
\hline Ordu & 3 & 0.6 & & & \\
\hline Nevşehir & 3 & 0.6 & & & \\
\hline Mersin & 3 & 0.6 & & & \\
\hline Denizli & 2 & 0.4 & & & \\
\hline Hatay & 2 & 0.4 & Tesis Sinif 1 & & \\
\hline Samsun & 2 & 0.4 & 5 Yildızlı & 290 & 67.4 \\
\hline Şanliurfa & 2 & 0.4 & 4 Yildızlı & 90 & 20.9 \\
\hline Çanakkale & 2 & 0.4 & 1. Sinif & 32 & 7.4 \\
\hline Kocaeli & 2 & 0.4 & 3 Yildizlı & 16 & 3.7 \\
\hline Erzurum & 2 & 0.4 & 2 Yildizli & 2 & 0.5 \\
\hline Kayseri & 2 & 0.4 & & & \\
\hline Bolu & 1 & 0.2 & & & \\
\hline Karabük & 1 & 0.2 & & & \\
\hline Kütahya & 1 & 0.2 & & & \\
\hline Mardin & 1 & 0.2 & & & \\
\hline Zonguldak & 1 & 0.2 & & & \\
\hline Yalova & 1 & 0.2 & & & \\
\hline Malatya & 1 & 0.2 & & & \\
\hline Sakarya & 1 & 0.2 & & & \\
\hline Giresun & 1 & 0.2 & & & \\
\hline Balıkesir & 1 & 0.2 & & & \\
\hline Tekirdağ & 1 & 0.2 & & & \\
\hline Sinop & 1 & 0.2 & & & \\
\hline Trabzon & 1 & 0.2 & & & \\
\hline
\end{tabular}

Çevreye duyarlı konaklama tesislerinin tesis sınıfına göre dağılımına bakıldığında; \%67,4'ü 5 yıldızlı, \%20,9'u 4 yıldızlı, \%7,4'ü 1. sınıf, \%3,7'si 3 yıldızlı, \%0,5'i 2 yıldızlı olarak görülmektedir.

Çalışmada tesislerin misyon ve vizyon kavramlarına ulaşmak için kullanılan alan resmi internet siteleridir. Bu sebeple ilk olarak tesislerin resmi internet sitelerinin varlığına bakılmıştır ve toplamda 478 tesisin 469 tanesinin resmi internet sayfasına ulaşılabilmiştir. 
Resmi internet sitelerinde misyon ve vizyon kavramlarının ulaşılabilirliğinde kavramların varlığı durumuna bakılmıştır ve toplamda 478 tesisin 106 tanesin de yani \%22,2 oranında misyon ve vizyon tanımlarının varlığına ulaşılmıştır. Bu bağlamda, hem misyon hem de vizyon tanımı \%66 oranında, sadece misyon tanımı \%19,8 oranında ve sadece vizyon tanımı $\% 14,2$ oranında sonuçlarına ulaşılmıştır (bk. Tablo 2).

Tablo 2. Çevreye Duyarlı Konaklama Tesislerinin İnternet Sitesi Varlığı Durumu ve Misyon \Vizyon Cümlesinin Varlığı Durumu

\begin{tabular}{|c|c|c|c|c|c|}
\hline \multicolumn{6}{|c|}{ IVIsyon I vizyon Cumesmin varmgi vurumu } \\
\hline İnternet Sitesi Varlığı Durumu & (f) & $\%$ & Misyon\Vizyon Cümlesinin Varlığı Durumu & (f) & $\%$ \\
\hline Resmi İnternet Sitesi Olan Tesisler & & & Otellerde Vizyon \Misyon Tanımının Her İkisi & & \\
\hline \multirow{3}{*}{ Resmi İnternet Sitesi Olmayan Tesisler } & 469 & 98.1 & de & 70 & 66.0 \\
\hline & & & Sadece Misyon Tanımı & 21 & 19.8 \\
\hline & 9 & 1.9 & Sadece Vizyon Tanımin & 15 & 14.2 \\
\hline
\end{tabular}

Tesislerin internet sitelerindeki misyon ve vizyon cümlelerinde Küresel Sürdürülebilir Turizm Konseyi' nin Kriterlerine ne kadar değinildiğine konseyin temel alan kriterleri ile birlikte bakılmıştır. $\mathrm{Bu}$ kriterler içerik analizi ile birlikte sınıflandırılmış ve sayısal verilerle özetlenmiştir. Bu bağlamda araştırmadaki konaklama tesislerinin yeşil yıldızlı olması nedenine ilaveten aynı zamanda misafirlerin farkındalığının da attırılması konusunda bu kriterlere ne kadar vurgu yapılıp yapılmadığını, bu kriterlerin ne kadar önemsenip önemsenmediğine bakılmıştır.

Genel olarak misyon ve vizyon cümlelerindeki kelime ve kavramlar ele alınarak değerlendirilmiştir. Çünkü misyon ve vizyon cümlelerinde kriterler hakkında detaylı olarak bilgi verilmemiştir. En çok çevre kriterine vurgu yapılmıştır. Temiz bir doğa ile iç içe kavramı sıklıkla kullanılmıştır. Sürdürülebilir yönetim kriterinde gelecek nesillere yaşanılır bir Dünya bırakmak kavramına vurgu yapılmıştır. Tesisin yeşil alanda bulunması, sürdürülebilir yaşam için sürekli olarak temiz ve güvenli çevre olanaklarının sunulması, doğanın korunması ve çevre kirliliğinin önlenmesi gibi kavramlara değinilmiştir. Yerel toplumda sosyal ve ekonomik faydaya yönelik olarak yerel istihdam, güven, ekonomi, sosyal gibi kavramlara değinilmiştir. Kültürel miras içerisinde tarihi ve kültürel zenginliklerin misafirlere tanıtımı ya da tarihi çevreye sahip olma gibi kavramlara vurgu yapılmıştır.

Tablo 3. Sürdürülebilir Turizm Kriterlerinin Alan Başlıklarının Misyon ve Vizyon Cümlelerinde Kullanım Dağılımı

\begin{tabular}{lll}
\hline Kriterler & (f) & $\%$ \\
\hline Çevre & 100 & 94.3 \\
Sürdürülebilir Yönetim & 96 & 90.6 \\
Yerel Topluma Sosyal ve Ekonomik Fayda & 45 & 42.5 \\
Kültürel Miras & 28 & 26.4 \\
\hline
\end{tabular}

Küresel sürdürülebilir turizm konseyinin tesisler için sürdürülebilir turizm kriterlerinin alan başlıklarının misyon ve vizyon cümlelerinde kullanım dağılımı; \%94,3'ü çevre, \%90,6's1 sürdürülebilir yönetim, \%42,5'i yerel topluma sosyal ve ekonomik fayda, \%26,4'ü kültürel miras sonuçlarına ulaşılmıştır (bk. Tablo 3).

Tablo 4. Sürdürülebilir Turizm Kriterlerinin Alan Başlıklarında Alt Kriter Olarak Bulunan Kelimelerin Dağılımı

\begin{tabular}{|c|c|c|c|}
\hline Kriterler & Alt Kriter Olarak Bulunan Kelimeler & $(\mathrm{f})$ & $\%$ \\
\hline \multicolumn{4}{|c|}{ ( } \\
\hline & Çevre Yönetimi & 50 & 50.0 \\
\hline & Çevre Dostu & 40 & 40.0 \\
\hline & Doğayı Koruma & 45 & 45.0 \\
\hline & Yeşil Alan & 55 & 55.0 \\
\hline & Çevreye Duyarlı & 60 & 60.0 \\
\hline & Doğal Yaşam & 68 & 68.0 \\
\hline & Atiklar & 25 & 25.0 \\
\hline
\end{tabular}




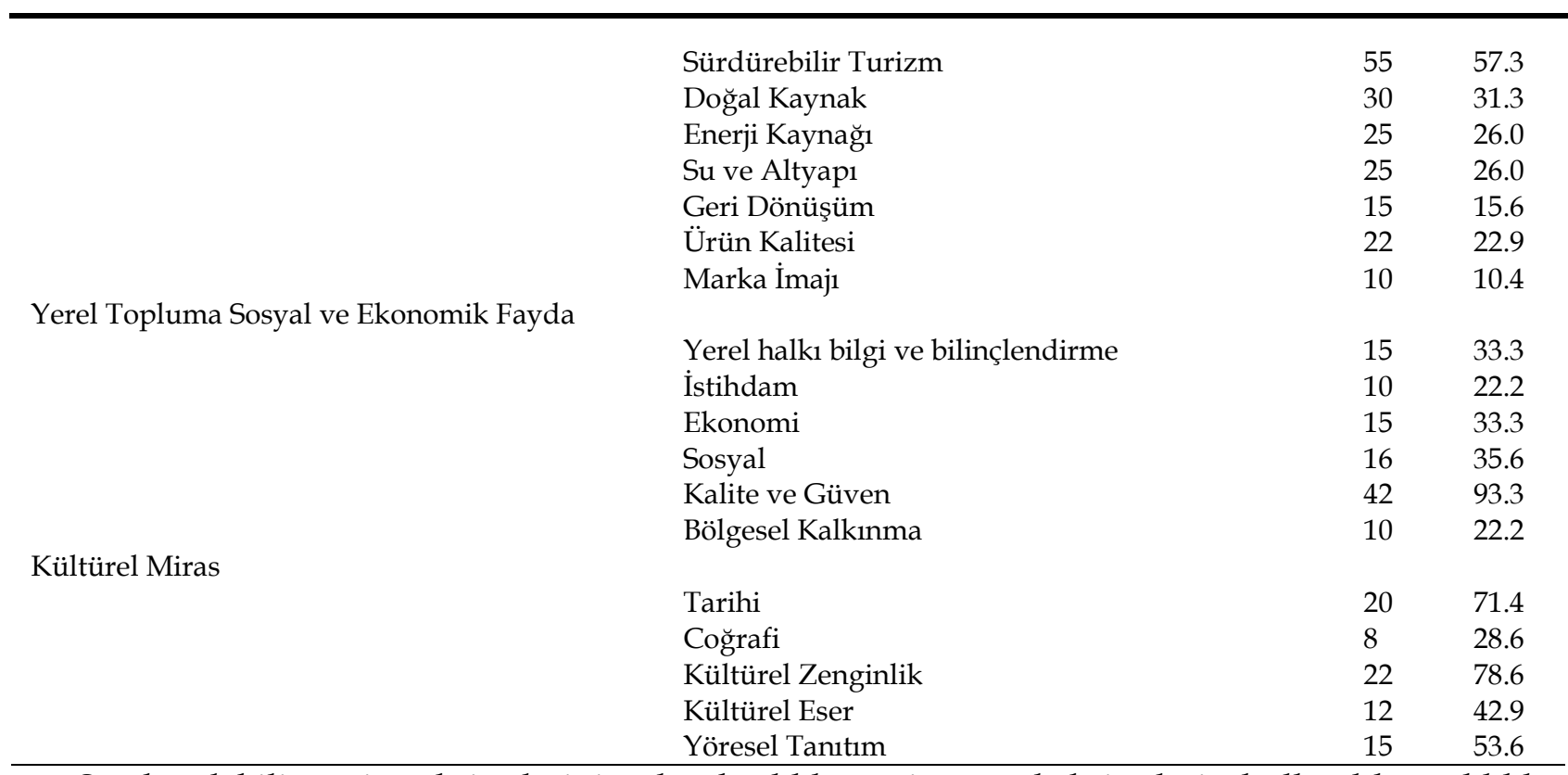

Sürdürülebilir turizm kriterlerinin alan başlıklarını içeren alt kriterlerin kullanıldığı sıklıklar Tablo 4 'de gösterilmektedir. Çevre kriterinin dağılımında en fazla \%68 oranı ile "doğal yaşam" alt kriterinin sıklıkla tekrarlandığı, sürdürülebilir yönetim kriterinin dağılımında en fazla \%57,3 oranı ile "sürdürebilir turizm" alt kriterinin sıklıkla tekrarlandığı, yerel topluma sosyal ve ekonomik fayda kriterinin dağılımında en fazla \% 93,3 oranı ile "kalite ve güven" alt kriterinin sıklıkla tekrarlandığ1 ve kültürel miras kriterinin dağılımında en fazla \%78.6 oranı ile "kültürel zenginlik" alt kriterinin siklıkla tekrarlandığı görülmektedir.

Konaklama tesislerinin internet sitelerine bakıldığında misyon ve vizyon tanımlarının dışında kriterleri içeren ödül ve politikalardan bahsedildiği görülmektedir. Kalite politikası, gıda güvenliği politikası, çevre politikası, sosyal sorumluluk politikası ve sürdürülebilirlik raporlarına değinilmektedir. Sürdürülebilir turizm kriterlerden politikalarda daha fazla detaya yer verilmiştir. Ayrıca internet sitelerinde yeşil yıldız, mavi bayrak, turuncu bayrak, yeşil anahtar, beyaz bayrak ve çevre dostu tesis ödülleri de gösterilmektedir.

Konaklama tesislerinin misyon ve vizyon tanımlarında misafir memnuniyeti de ön planda tutulmuştur. Uluslararası alanda güçlü bir marka olmayı da hedeflemişlerdir.

\section{Sonuç ve Değerlendirme}

Sürdürülebilirlik, günümüzde ve gelecekte sürdürülebilir kalkınmayı diğer kuşaklara aktarılmasında önemli bir rol oynamaktadır. Turizm profesyonel bakış açısıyla gelişmediği durumda çevreye ciddi zararlar verebileceğinden sürdürülebilirlik, turizm sektöründe temel prensip olmalıdır. Bu nedenden ötürü konaklama tesisleri de çevreye duyarlı tesis anlayışını her geçen gün daha fazla benimsemeye başlamış ve çevrecilik kavramı giderek önem kazanmıştır. Konaklama tesisleri kendi talepleri doğrultusunda Kültür ve Turizm Bakanlığg'nın belirlediği kriterler ile Çevreye Duyarlı Konaklama Tesisi Belgesi alabilmektedirler. Çalışmada, öncelikle Çevreye Duyarlı Konaklama Tesis Belgesine sahip konaklama tesislerinin internet sitelerinde misyon ve vizyon cümlelerinin varlığı incelenmiştir. Tesislerin internet sitelerinde genellikle kurumsal ve hakkında başlığı altında misyon ve vizyon tanımları bulunmaktadır. Konaklama tesislerinin \%22,2'sinin internet sitesinde misyon ve vizyon tanımlarına ulaşılmıştır. Tesislerin büyük çoğunluğunda misyon ve vizyon tanımlarına ulaşılamamıştır oysaki tesis tanıtımında misyon ve vizyon tanımları önem arz etmektedir. İşletmeler için bir kimlik görevi gören misyon ve vizyon tanımlarının önemsenmemesi bir tesis için büyük bir eksikliktir. Çevreye duyarlı konaklama tesislerine ait olan misyon ve vizyon cümlelerinde tanıtım için etkin bir kullanımın söz konusu olmaması da diğer bir eksikliktir. Ulaşılan misyon ve vizyon cümlelerine bakıldığında yapılan vurgularda çevreye duyarlı tesis olmalarına rağmen çevre ile ilgili yeterli bilgiye yer verilmemektedir. Günümüzün yoğun rekabet ortamında avantaj sağlayacak her türlü unsur önem 
arz etmektedir. Misyon ve vizyon cümlelerinde sürdürülebilir turizm kriterleri dikkate alınarak sadece kelime ve kavramlar ele alınıp dağılım yapılmıştır. Sürdürülebilir turizmin önemli kriterleri, çevreye duyarlı tesisler için de önemli olmalıdır. Çevreye duyarlılık ve sürdürülebilir turizm kriterlerine tesisler daha çok politikalarında değinmişlerdir. Konaklama tesislerinin internet sitelerinde kalite politikası, gıda güvenliği politikası, çevre politikası sosyal sorumluluk politikası ve sürdürülebilirlik raporları bulunmaktadır. Tesislerin çevreye duyarlılık konusunda internet sitelerinde sertifika ve ödülleri daha fazla yansıttıkları görülmektedir. Konaklama tesislerinin internet sitelerinde politikalar adı altında yapılan faaliyetler ve etkinliklerden bahsedilmektedir. Turistler çevreye duyarlı, özgün ve bozulmamış doğal, kültürel, tarihi kaynaklar gibi sürdürülebilir turizm uygulanmalarına önem vermektedir. Tesis alanlarının sürdürülebilir turizm kriterleri doğrultusunda revize edilmesi, misafirlerde memnuniyet yaratan bir uygulama olacaktır. Konaklama tesisleri, misafirlerin istek ve ihtiyaçlarına göre kişiye özgü ve farklı deneyimler sunarken farklılaşmayı da sağlayarak avantaj elde edebilmektedirler. Turistlerin çevreye duyarlı tesisleri tercih etme nedenleri her geçen gün artmaktadır. Misyon ve vizyonun bir işletmenin amaç ve hedeflerini oluşturduğu bilincine göre önem verilip tanımlarının bulunması gerekmektedir. Konaklama tesisleri misafirlere internet sitelerinde tanıtıcı faaliyetler ile birlikte bilgilendirme yapabilirler. Böylelikle internet sitelerini daha etkili ve çekici olması sağlanabilir. Sürdürülebilir ürünler isteyen tüketiciler için misyon ve vizyon cümlelerindeki sürdürülebilirlik ile ilgili atıflarda bulunabilirler ve çevreye duyarlılığı atfetmiş olurlar. Böylece çevreye duyarlı konaklama tesisleri diğer konaklama tesislerine göre daha fazla satın alma davranışları gerçekleştirmiş olurlar. Günümüzde turistler tesis tercihi yaparken interneti önemli bir bilgi kaynağ 1 olarak kullanırlar. Bu şekilde misafirlerin farkındalığı da artmış olur ve satın almaları için ikna şansı artabilir. Dolayısıyla tesisler misyon, vizyon, çevreye duyarlılık ve sürdürülebilir turizm kriterlerine internet sitelerinde de önem vermeli ve bu olguları ön plana çıkararak daha fazla değinmesi gerekmektedir. Sürekli değişen ve rekabet şiddetinin arttığı bir ortamda her daim başarının da sürdürülebilmesi için konaklama tesisleri bu faaliyetlere daha çok dikkat etmesi gerekmektedir. Bu çalışmanın sonuçları doğrultusunda çevresel farkındalık düzeyi ile merkezi ve yerel yönetimlerin arttırılması öneri olarak sunulabilir. Diğer yandan çevreye duyarlılık sertifikaları ile ilgili konaklama işletmelerine yönelik eğitim kurslarına ilişkin desteğin sağlanması ve politika yapıcıların çevreyi korumak adına yeni hukuki düzenlemeler getirilmesi de öneri olarak araştırma kapsamında verilebilir. Ülke dışında yer alan çevreye duyarlı konaklama işletmelerinin çevresel alandaki çalışmaları ve bu çalışmalar için kullanılan teknolojilerin Türkiye' deki konaklama işletmelerine de aynı şekilde uygulanması tavsiye edilebilir. Ayrıca tur operatörleri ve seyahat acentelerinin, turizm pazarlamasında çevreci konaklama işletmelerini göz önünde bulundurarak çevre konusundaki işbirliklerini arttırmaları sağlanabilir.

\section{Kaynakça}

Acuner, E. (2015). Zigana Turizm Merkezi'nin sürdürülebilir turizm kriterleri çerçevesinde yerel destinasyon yönetim örgütleri tarafından değerlendirilmesi. Gazi Üniversitesi Turizm Fakültesi Dergisi, 1, 62-93.

Akdağ, G., Güler, O. Demirtaş, O. Dalgıç, A. ve Yeşilyurt, C. (2014). Turizm ve çevre ilişkisi: Türkiye'deki yeşil otellerin gözünden yeşil otelcilik uygulamaları üzerine bir değerlendirme. Coğrafyacılar Derneği Uluslararası Kongresi Bildirileri, Muğla, 258-267.

Akdemir, N. (2019). Kış turizm merkezlerinde çevre duyarlılığı, yaklaşım ve çözümler: Palandöken otelleri örneği. Uluslararası Türk Dünyası Turizm Araştırmaları Dergisi, 4(1), 1-16.

Akoğlan Kozak, M., Evren, S. ve Çakır, O. (2013). Tarihsel süreç içinde turizm paradigması. Anatolia: Turizm Araştırmaları Dergisi, 24(1), 7-22.

Akova, O., Yaşar, A. G. Aslan, A. ve Çetin, G. (2015). Çalışanların çevre yönetimi algıları ve örgüt kültürü ilişkisi: Yeşil yıldızlı otellere yönelik bir araştırma. İşletme ve Yönetim Araştırmaları Dergisi, 2(2), 169-184. 
Ardıç Yetiş, Ş. A. (2018). Sürdürülebilir turizm kapsamında küçük ölçekli konaklama işletmelerinde yeşil pazarlama uygulamaları. Gümüşhane Üniversitesi Sosyal Bilimler Enstitüsü Elektronik Dergisi, 9(23), 82-98.

Aylan, F. K. ve Sezgin, M. (2016). Turistlerin yeşil otellere yönelik düşünceleri ve kalma niyetleri: Antalya'da bir araştırma. Uluslararası Turizm ve Sosyal Araştırmalar Dergisi, (1), 285-300.

Büyükşalvarcı, A., Şapçılar, M. C. ve Akuğur, Ş. B. (2017). Otel işletmelerinde çevre duyarlılığı ve yeşil yıldız uygulamaları üzerine bir araştırma. Yönetim, Ekonomi ve Pazarlama Araştırmaları Dergisi, 1(1), 25-35.

Çavuşoğlu, S. ve Durmaz, Y. (2019). Yeşil davranışlara karşı tutumun ziyaret niyetine etkisinde yeşil imajın düzenleyicilik rolü: Yeşil oteller örneği. Sosyal Bilimler Dergisi, 29(2), 303-315.

Çevreye duyarlılık kampanyası (yeşil yıldız). (2020). https://yigm.ktb.gov.tr/TR-11596/cevreyeduyarlilik-kampanyasi-yesil-yildiz.html. (03.04.2020).

Civelek Oruç, M. ve Zengin, B. (2015). Misyon vizyon bildirilerinin müşteri odaklılık yönünden değerlendirilmesi: 5 yıldızlı konaklama işletmeleri örneği. İktisadi ve İdari Bilimler Dergisi, (9), 3149.

Cömert, M. ve Özata, E. (2016). Sürdürülebilir turizm kapsamında yeşil yıldız çevreye duyarlılık projesi. Uluslararası Sosyal Araştırma Dergisi, 9(47), 1169-1178.

Deste, M., Binbaşığlu, H. ve Türk, M. (2018). Konaklama işletmelerinde atık yönetimi ve geri dönüşüm: İnönü Üniversitesi Kale Göl Otel örneği. Anemon Sosyal Bilimler Dergisi, 6(2), 225-234.

Dilek, E. ve Atay, L. (2012). Antalya'daki beş yıldızlı otellerin yeşil otelcilik uygulmaları üzerine bir araştırma. İşletme Fakültesi Dergisi, 13(2), 61-90.

Doğan, Ö. ve Ertaş, F. C. (2018). Çevreye duyarlılığın rekabet gücüne etkisi: Yeşil yıldızlı oteller üzerine bir uygulama. Maliye ve Finans Yazlları, (110), 217-234.

Doğancili, O. S. ve Akbulut, B. A. (2015). Yeşil yıldız çevre etiketine sahip otellerin web sitelerinde yeşil pazarlamayı kullanmalarına ilişkin içerik analizi. 16. Ulusal Turizm Kongresi, Çanakkale,402-417.

Çetin Gürkan, G., Dönmez Polat, D. ve Demiralay, T. (2015). Turistlerde çevre bilincinin çevreye duyarlı konaklama işletmelrinde kalma tercihleri üzerindeki etkisi. Ekonomi ve Yönetim Araştırmaları Dergisi, 4(1), 114-133.

Ertaş, Ç. (2018). Yeşil yıldızlı konaklama işletmelerinin İnternet sitelerindeki çevresel içerik üzerine bir inceleme. Türkiye Sosyal Araştırma Dergisi, (3), 97-820.

Ertaş, M., Kırlar Can, B., Yeşilyurt, H. ve Koçak, N. (2017). Konaklama işletmelerinin yeşil yıldız uygulamaları kapsamında çevreye duyarlılığının değerlendirilmesi. Seyahat ve Otel İşletmeciliği Dergisi, 15(1), 102-119.

Giritlioğlu, İ. ve Güzel, M. O. (2015). Otel işletmelerinde yeşil yıldız uygulamaları: Gaziantep ve Hatay bölgesinde bir araştırma. Uluslararası Sosyal Araştırmalar Dergisi, 8(40), 889-904.

Global Sustainable Tourism Council - Küresel Sürdürülebilir Turizm Konseyi (GSTC). (2020). https://certifications.controlunion.com/tr/certification-programs/certificationprograms/global-sustainable-tourism-council-kueresel-suerdueruelebilir-turizm-konseyi-gstc. (05.04.2020).

Gönen, İ. (2018). Otelcilik sektöründe yeşil işletme çalışmaları. Uluslararası İşletme ve Pazarlama Kongresi Bildirileri, 351-360.

GSTC. (2016, Aralık). Oteller için GSTC endüstri kriterleri raporu. Küresel sürdürülebilir turizm kriterleri. https:/ / www.gstcouncil.org. (05.04.2020).

Gümüş, M. (2014). Sürdürülebilir turizm kapsamında yatırım projelerinin değerlendirilmesi: Konya'da yeşil yıldız çevreye duyarlı termal otel yatırımı örneği. Selçuk Üniversitesi Sosyal Bilimler Enstitüsü, Konya.

Güneren, E. ve Karakuş, Y. (2015). Turizmde postmodern pazarlama. Turizm pazarlamasında güncel yaklaşımlar (Ed.B. Kılıç ve Z. Öter) Beta, İstanbul, 455-487.

Güneş, G. (2011). Konaklama sektöründe çevre dostu yönetimin önemi. Sosyal ve Ekonomik Araştırmalar Dergisi, 13(20), 45-51. 
Güngör, Y., Karacan, S. ve Karacan, E. (2018). Yerel işletmeler sürdürülebilir turizm ve Kartepe. Uluslararası Turizm, İsletme, Ekonomi Dergisi, 2(2), 225-233.

Güzel, Ö. (2014). Postmodern çağ tatil deneyimlerinde hazcı tepki basamağı çıktısı olarak temalı oteller. Uluslararasi İktisadi ve İdari İncelemeler Dergisi, (13), 1-15.

İnce, A. R. (2015). Türkiye'nin ikinci 500 büyük şirketinin misyon ve vizyon ifadelerine göre girişimcilik özellikleri. İktisadi ve İdari Bilimler Fakültesi Dergisi, 8(2), 143-155.

Kement, Ü. (2018). Çevresel kayg1 ve algılanan ahlaki yükümlülügüü yeşil otelleri ziyaret etme niyetine etkisinin incelenmesi. Turizm Akademik Dergisi, 5(2), 203-214.

Kement, Ü. ve Çavuşoğlu, S. (2017). Hafızaya yönelik müşteri deneyimlerinin müşteri sadakatine etkisi: Yeşil oteller örneği. Uluslararası Sosyal ve Eğitim Bilimleri Dergisi, 4(8), 172-194.

Kılıç, M. (2010). Stratejik yönetim sürecinde değerler, vizyon ve misyon kavramları arasındaki ilişki. Sosyoekonomi Dergisi, 2, 81-97.

Kim, S.H. (2009). An Investigation Into Hotel Employees' Perception Of Green Practices.StarsUniversity of Central Florida, Orlando, Florida.

McNamara, K. E. \& Gibson, C. (2008). Environmental sustainability in practice? A Macro-scale profile of tourist accommodation facilities in Australia's coastal zone. Journal of Sustainable Tourism, 16(1), 85-100.

Mercan, Ş. O. (2016). Lisans düzeyinde turizm eğitimi alan öğrencilerin otel işletmelerini çevre duyarlılığ1 açısından değerlendirmeleri. Karabük Üniversitesi Sosyal Bilimler Enstitüsü Dergisi, 6(1), 126-144.

Mesci, Z. (2014). Otellerin çevreci uygulamalarının değerlendirilmesi: yeşil yıldızlı bir otel işletmesinde örnek olay çalışması. Seyahat ve Otel İşletmeciliği Dergisi, 11(1), 90-102.

Muslu, Ş. (2014). Örgütlerde misyon ve vizyon kavramlarının önemi. HAK-İS Uluslararası Emek ve Toplum Dergisi, 3(5), 151-171.

Oğuz, Y. E. ve Yılmaz, V. (2019). Çevre bilincinin yeşil yıldızlı otel tercihine etkisi: ESOGÜ Turizm Fakültesi öğrencileri örneği. Eskişehir Osmangazi Üniversitesi İIBBF Dergisi, 14(1), 51-66.

Öğülmüş, S. (1991). İçerik çözümlemesi. Ankara Üniversitesi Eğitim Bilimleri Fakültesi Dergisi, 24(1), 213-228.

Özdemir Y1lmaz, G., Özok, O. ve Erdem, B. (2016). Konaklama işletmelerinde çevre dostu uygulamalar: Bodrum örneği. Sosyal Bilimler Enstitüsü Dergisi, 6(1), 180-197.

Özer, L., Kement, Ü. ve Gültekin, B. (2015). Genişletilmiş Planlanmış Davranış Teorisi kapsamında yeşil yıldızlı otelleri tekrar ziyaret etme niyeti. İktisadi ve İdari Bilimler Fakültesi Dergisi, 33(4), 5985.

Rani, G. P. \& Raj, C. (2020). Green human resource practices and job satisfaction of star hotel employees in kanyakumari district. UGC Care Journal, 40(18), 2255-2263.

Sabuncuoğlu, A. ve Gök, O. (2008). Büyük işletmelerin web sitelerinde yer alan misyon ve vizyon ifadelerinin pazar odaklılık açısından değerlendirilmesi. İktisat İdari Bilimler Fakültesi Dergisi, 5(1), 123-141.

Satar, İ. ve Güneş, G. (2017). Turizm Sertifikasyonu: Ankara Radısson Blu Otel'de örnek uygulama. Sosyal Bilimler Dergisi, 8(2), 28-46.

Soygür, İ. C. (2018). Kamu ile yerli ve yabancı özel sektör bankalarının vizyon ve mizyon farkları üzerine bir değerlendirme. Süleyman Demirel Üniversitesi İktisadi ve İdari Bilimler Fakültesi Dergisi, 23(3), 987-1004.

Tayara, M. ve Özel, Ç. H. (2019). Annals of Tourism Research Dergisinde yayımlanan postmodern dönemde turizm konulu makaleler: Bibliyometrik inceleme. Anatolia: Turizm Araştırmaları Dergisi, 30(2), 100-111.

Türk, M. ve Harbalıŏlu, M. (2015). Konaklama işletmelerinde çevreye duyarlılık. Akademik Sosyal Araştırmalar Dergisi, (14), 419-428.

Türk, M. ve Kara, E. (2018). Konaklama işletmelerinde çevre bilinci ve yeşil yönetim uygulamalarının işletme başarısına katkısı: Muğla ili üzerine bir araştırma. Uluslararası Toplum Araştırmaları Dergisi, 8(15), 848-876. 
Ünüvar, Ş. (2016). Konya'da faaliyet gösteren turizm işletme belgeli konaklama tesislerinde çevreye duyarlı tesis simgesi-yeşil yıldız üzerine bir araştırma. Sosyal Bilimler Meslek Yüksekokulu Dergisi, 19, 97-110.

Verma, V. K. \& Chandra, B. (2016). Hotel guest's perception and choice dynamics for green hotel attribute: a mix method approach. Indian Journal of Science and Technology, 9(5), 1-9.

Yıldırım, H. M., Sünnetçioğlu, A. ve Atay, L. (2018). Yaşam tarzının yeşil otel tercihinde rolü. Sosyal Bilimler Dergisi, 6(18), 9-17.

Yıldız, B. ve Kılıç, S. N. (2016). Alman turistlerin çevre bilinci ve çevre dostu otel (yeşil otel) algısının davranışsal niyetleri üzerine etkisi. Uluslararası Sosyal Araştırmalar Dergisi, 9(43), 2614-2623.

Yurtsal, K. (2019). Türkiye'de sürdürülebilir turizm. Sivas Interdisipliner Turizm Araştırmaları Dergisi, 61-69.

Zengeni, N., Monica, D., Zengeni, F. \& Muzambi, S. (2013). Hoteliers' perceptions of the impacts of green tourism on hotel operating costs in Zimbabwe: The case of selected Harare Hotels. Australian Journal of Business and Management Research, 2(11), 64-73.

\section{Aim and Scope}

\section{Extended Abstract}

In this study, it is aimed to calculate and reveal the distribution of the expressions in the missions and visions of environmentally friendly accommodation facilities depending on the basic areas of sustainable tourism criteria through relevant data. The population of the study consists of accommodation facilities with the label of an environmentally friendly facility in Turkey. The names of the relevant facilities were obtained from the official website of the Ministry of Culture and Tourism. There are a total of 478 environmentally friendly accommodation facilities (facilities with green star).

\section{Method}

The theoretical background of the study is based on the attribution theory. Content analysis screening method was used in the study. The websites of the facilities included in the list of "environmentally friendly facilities" were visited between 07.04.2020 and 16.04.2020. In the study, first, the percentage and frequency distributions of facility type, facility class data, and provinces where accommodation facilities with a certificate of an environmentally sensitive facility are located were examined. In the study, the accessibility to the internet sites of the facilities was examined. The facilities with a website were checked whether they have mission and vision sentences, and sentence structures related to the basic areas of sustainable tourism criteria were determined from the existing mission and vision sentences.

\section{Findings}

478 environmentally sensitive accommodation facilities (facilities with green star) in Turkey are scattered over a total of 36 provinces and Antalya has the most accommodation facilities having a green star with 245 facilities. Antalya covers $51.3 \%$ of the environmentally friendly accommodation facilities with 245 facilities. The top five involves İstanbul with 64 facilities (\%13, 4), Muğla with 49 facilities (\%10, 3), İzmir with 29 facilities $(\% 6,1)$ and Ankara with 21 facilities $(\% 4,4)$. When the distribution of environmentally friendly accommodation facilities by facility type is examined, it is seen that there are 380 hotels and they cover $79.5 \%$ of the total facilities with this number. The number of holiday villages covering $6.7 \%$ of the facilities is 32 . The top five includes thermal hotels (18), private facilities (17), and boutique hotels (13). When the distribution of environmentally friendly accommodation facilities by facility class is examined, it is seen that $\% 67,4$ of them are fivestar, $20.9 \%$ are four-star, $\% 7,4$ are first class, $\% 3,7$ are three-star, and \%0,5 are two-star. The official websites of 469 facilities were accessed. The absence of definitions belonging to mission and vision that serve as an identity for businesses is one of the important deficiencies. When the mission and vision sentences obtained are examined, it is seen that although they are environmentally sensitive facilities, their mission and vision sentences do not include sufficient information about the 
environment. Instead, the facilities refer to the phrases about "environmental awareness" and "sustainable tourism criteria" within the framework of their business policies. The facilities mostly display their certificates and awards for environmental awareness on their websites. The facilities reflect the certificates and awards they have on environmental awareness more on their websites. Mission and vision definitions were detected in 106 (22.2\%) of 478 facilities. Therefore, it was concluded that many facilities still do not have an accessible mission and vision definition. When the distribution of the use of the titles of sustainable tourism criteria in the mission and vision statements is examined, it is seen that $\% 94,3$ of the titles are about the environment, $\% 90,6$ are about sustainable management, $\% 42,5$ are about social and economic benefit to the local community, and $\% 26,4$ are about cultural heritage. Facilities also prioritize guest satisfaction in their mission and vision definitions. Being a strong brand in the international arena is among the other goals of the facilities.

\section{Conclusion}

Based on the fact that mission and vision constitute an important part of the goals and objectives of the business, importance should be attached to the concepts and businesses should include mission and vision definitions in accessible areas (web pages, etc.). The reason for this is that tourists of today use the internet as an important source of information when choosing a facility. Thus, the guests' level of persuasion for their purchases can be increased by positively affecting their awareness. Therefore, facilities should give importance to the mission, vision, environmental awareness and sustainable tourism criteria on their websites, moreover, they should highlight these facts and mention them in accessible areas. 